\title{
GAYA BAHASA DAN FUNGSI DALAM NOVEL 红高粱 (HONG GAOLIANG) KARYA MO YAN
}

\author{
Niza Ayuningtias, S.S., MTCSOL/ Indah Sari, S.S \\ Program Studi Sastra Cina, Fakultas Ilmu Budaya, Universitas Sumatera Utara \\ niza.ayuningtias@yahoo.com
}

\begin{abstract}
Literature (novel) uses language as a means of communication. Thus, language plays an important role in expressing a writer's thought. The title of the research was "The Analysis on Figurative Style in the Novel, 红高粱 (hóng gāoliang), by Mo Yan.” In this research, the writer analyzed Mandarin figurative style found in the novel, 红高粱 (hóng gāoliang). The research used the concept of Mandarin figurative style by Huang and Liao and descriptive qualitative method. The data of Figurative Style was obtained from the novel, 红高粱 (hóng gāoliang) by Mo Yan, published in 2012. The result of the research showed that there were nine types of figurative style in the novel, 红高粱 (hóng gāoliang) by Mo Yan: figurative style of 比喻(bǐyù), 比拟(bǐnǐ), 夸张 (kuāzhāng), 借代(jièdài), 反语(fănyǔ), 层递(céng dì), 反复(fănfù), 映衬(yìngchèn), and 对偶 (dui'ǒu). The role of figurative styles was as follows: 1) 比喻(bǐyù) figurative style gave the effect of beauty in the story, made the content of the story more interesting and concrete, and gave profound impression to the readers, 2) 比拟(bǐnǐ) figurative style made the story more interesting, more animated, and not monotonous , 3) 夸张(kuāzhāng) figurative style changed the simple language to an interesting one, 4) 借代(jièdài) figurative style made the language and the words varied, 5) 反语(fănyǔ) figurative style expressed satire and the sentence looked humorous, 6) 层 递(céng dì) figurative style gave the impression of greatness, 7) 映祄(yìngchèn) figurative style made the atmosphere in the story more expressive, 8) 反复(fãnfù) figurative style emphasized on a problem and expressed a certain feeling, and 9) 对偶(duì'ǒu) figurative style gave explicit intention to its readers.
\end{abstract}

Keyword: Literature, Novel, Figurative Style

\section{A. PENDAHULUAN}

Bahasa dan sastra merupakan dua hal yang tidak dapat dipisahkan, sastra merupakan bentuk dari karya seni yang menggunakan bahasa sebagai sarana (media) penyampaiannya. Bahasa digunakan sastrawan sebagai media untuk menyampaikan ide atau gagasannya kepada masyarakat luas. Bahasa menjadi jembatan yang menghubungkan sastrawan dengan khalayak. Melalui sastra, penulis mengeksploitasi potensi-potensi bahasa untuk menyampaikan gagasannya untuk tujuan tertentu. Bahasa menjadi bahan utama sastra, maka untuk memahami karya sastra 
penguasaan bahasa diperlukan. Pengarang dalam sastra memiliki imajinasi yang berbeda-beda sehingga menghasilkan karya sastra yang memiliki beragam jenis gaya bahasa majas.

Salah satu bentuk karya sastra yang banyak di temukan adalah novel. Novel merupakan sebuah karya fiksi prosa yang ditulis secara naratif, biasanya dalam bentuk cerita, novel terdiri dari 40.000 kata, dan lebih kompleks dari cerpen. Novel merupakan hasil ciptaan seorang penulis, yang bersifat imajinatif, karena di dalam novel terkandung cerita-cerita yang indah.

Untuk mengekspresikan pengalaman dan menghidupkan karangan, seorang pengarang menggunakan gaya bahasa majas. Salah satu bagian dari gaya bahasa adalah majas atau figurative language. Majas/bahasa figuratif ialah bahasa yang maknanya melampaui batas yang lazim, Oleh karena itu majas erat kaitannya dengan diksi. Selanjutnya diksi atau pilihan kata yang tepat akan memperkuat gaya bahasa. Jadi, majas juga merupakan alat untuk menunjang gaya bahasa. Semakin jelas bahwa majas seperti simile, metafora, personifikasi merupakan salah satu unsur gaya bahasa. Setiap gaya bahasa mempunyai peranan tersendiri untuk mengungkapkan pikiran pengarang, agar karya yang dibuat menjadi lebih indah untuk dibaca dan pengarang sastra biasanya menggunakan gaya bahasa tertentu pada setiap karyanya.

Gaya bahasa dalam novel 红高粱 (hóng gāoliang) karya Mo Yan ini, diharapkan dapat memberi pengetahuan terhadap penikmat sastra, agar para pembelajar bahasa Mandarin tidak hanya mengetahui ragam linguistik tetapi juga dapat mengetahui ragam sastra, khususnya bahasa majas dalam bahasa Mandarin.

Penelitian ini bertujuan untuk mendeskripsikan gaya bahasa dalam novel Hong Gaoliang karya Mo Yan, dan menentukan fungsi gaya bahasa yang terdapat dalam novel 红高粱 (hóng gāoliang) karya Mo Yan. Metode yang digunakan yaitu deskriptif kualitatif. Pendekatan deskriptif kualitatif dilakukan dengan memusatkan kepada memaparkan teks dan mengklarifikasinya.

Penelitian ini menggunakan teori stilistika Nurgiyantoro. Nurgiyantoro (1995: 290) membuat simpulan bahwa unsur gaya bahasa terdiri dari unsur leksikal, gramatikal, retorika, dan kohesi. Unsur retorika meliputi pemajasan, penyiasatan struktur kalimat, dan pencitraan. Dengan demikian, style atau gaya bahasa terdiri dari unsur leksikal, gramatikal, kohesi, dan retorika. Dalam penelitian ini unsur gaya bahasa yang digunakan adalah unsur retorika. Pembahasan unsurunsur gaya bahasa yang menjadi objek dalam penelitian ini adalah unsur retorika yang meliputi pemajasan. 
Adapun tahapan analisis data dalam penelitian ini adalah: menelaah seluruh data yang diperoleh berupa gaya bahasa dalam novel 红高粱(hóng gāoliang) karya Mo Yan, mereduksi dan mengaitkan data tertulis berupa gaya bahasa yang ditemukan dalam kartu data. Selanjutnya, untuk memperkuat analisis senantiasa dikutip gaya bahasa sesuai dengan yang dianalisis, misalnya gaya bahasa personifikasi dan berapa banyak ditemukan dalam novel tersebut, berikutnya mengadakan pemeriksaan keabsahan data berupa gaya bahasa yang telah di temukan sebagai hasil penelitian.

\section{B. PEMBAHASAN}

\subsection{Gaya Bahasa dalam Novel 红高粱 (hóng gāoliang) Karya Mo Yan}

\subsubsection{Gaya Bahasa 比喻(bǐyù)}

比喻(b̌̌yù) merupakan gaya bahasa perumpamaan, gaya bahasa 比喻(b̌̀yù) mengibaratkan atau menggambarkan suatu hal terhadap manusia atau benda. 比喻(b̌̀yù) adalah gaya bahasa yang membandingkan suatu benda dengan keadaan lain yang sesuai dengan keadaan yang dilukiskannya sehingga menimbulkan tanggapan dengan benda yang di bandingkan.

Menurut Huang dan Liao (2008) gaya bahasa 比喻(b̌̌yù) menggunakan objek yang berbeda tetapi mempunyai kesamaan untuk menggambarkan atau menjelaskan suatu logika.. 比喻(b̌̀yù) terbagi atas tiga yaitu: 明喻(míngyù), 暗喻(ànyù), 借喻 (jièyù), 明喻(míngyù) dicirikan oleh beberapa leksikal yaitu :像, 如, 似, 仿佛, 猶如, 一船, 像...似的. 暗喻(anyù) dapat disebut juga dengan 隠喻(yı̌nyù), 暗喻 (ànyù) dicirikan oleh beberapa leksikal yaitu : 是, 变成, 成为，等于. Sedangkan 借喻(jièyù) dicirikan oleh leksikal 无.

Pada halaman 3 dalam novel 红高粱(hóng gāoliang) terdapat gaya bahasa 比喻(bìyù) seperti berikut ini:

奶奶像岸愈离愈远，雾像海水愈近愈汹涌，父亲抓住余司今，就像抓住一条船舷。

Artinya: Nenek memudar seperti pantai di kejauhan saat lautan kabut yang mendekat semakin bergejolak; merengkuh komandan Yu bagaikan menggantung dipagar perahu.

Pada penggalan kalimat tersebut dipaparkan bahwa salah satu ciri gaya bahasa b̌̌yù (比喻) secara eksplisit menggunakan kata xiàng (像) yang artinya adalah seperti, pada kalimat "nenek memudar seperti pantai" kata nenek merupakan subjek dan merupakan manusia yang di kaitkan dan di gambarkan memudar seperti pantai karena pantai semakin dari jauh terlihat semakin 
Vol.1, No.2, Oktober 2017, PP.37-48

E-ISSN 2579-4906

menjauh dan memudar, sehingga pengarang mengaitkan antara nenek dan pantai karena berhubungan dengan citra nenek yang semakin lama semakin pudar seperti layak nya lautan kabut yang berarti semakin tidak terlihat dan tidak terpandang.

\subsubsection{Gaya Bahasa 比拟(bǐnǐ)}

比拟(bǐnǐ) adalah gaya bahasa yang mengibaratkan benda seolah-olah hidup seperti manusia atau manusia seolah-olah seperti benda. Gaya bahasa 比拟(b̌̌ň̌) juga yang memberikan sifat-sifat manusia pada benda mati, dan membandingkan sesuatu dari benda mati seolah-olah menjadi benda hidup.

Contoh:

公路笔直地往南去，愈远愈窄，最后被高粱淹没。

Artinya : Jalan raya membentang ke selatan, pita jalanan berliku-liku menyempit yang akhirnya ditelan ladang sorgum.

Pada penggalan kalimat berikut" Jalan raya membentang ke selatan, pita jalanan berlikuliku menyempit yang akhirnya ditelan ladang sorgum” merupakan gaya bahasa 比拟 (b̌̌ň̌)karena pada kalimat diatas tergambarkan bahwa "pita jalanan" yang merupakan wujud benda yang terbentang kearah selatan, dan sepanjang jalan raya yang membentang kearah selatan terdapat liku-liku jalanan dan di sepanjang liku-liku jalan raya yang membentang kearah selatan terdapat ladang sorgum, jadi pengarang menceritakan didalam novel tersebut karena sorgum lebih banyak dibandingkan dengan liku-liku jalanan sehingga pengarang menceritakan seolah-olah jalanan yang berliku menyempit dan ditelan ladang sorgum, terlihat jelas bahwa pita jalanan yang merupakan wujud benda dapat menelan ladang sorgum, yang seakan benda yang tidak hidup tersebut menjadi hidup dan dapat menelan seolah tergambarkan seperti benda hidup.

\subsubsection{Gaya Bahasa 夸张(kuāzhāng)}

Gaya bahasa 夸张( kuāzhāng) adalah gaya bahasa yang melebih-lebihkan keberadaan dari suatu benda atau orang tersebut, termasuk gaya kiasan untuk menyatakan suatu benda, hal atau peristiwa dengan cara melebih-lebihkannya.

Contoh:

父亲瘦弱的身体在河堤上跑着，父亲高大雄伟漂亮，父亲高叫着。

Artinya: Ayah tampak menakjubkan, ayah terlihat indah 
Pada penggalan kalimat di atas terlihat terdapat gaya bahasa 夸张(kūazhāng), gaya bahasa ini digunakan oleh pengarang dengan menggunakan ciri leksikal kata $g \bar{a} o$ (高), kata gāo(高) memiliki arti tinggi, gaya bahasa 夸张(kuāzhāng) pada penggalan kalimat di atas terdapat pada kata ayah tampak menakjubkan, menakjubkan merupakan kata yang memiliki arti hal yang sangat luar biasa dan ayah terlihat indah, didalam cerita tokoh ayah diceritakan dengan dilebih-lebihkan keberadaannya, karena dalam kata menakjubkan seorang ayah sudah terlihat bahwa tokoh ayah seorang yang luar biasa.

\subsubsection{Gaya Bahasa 借代(jièdài)}

Gaya bahasa 借代(jièdài) merupakan gaya bahasa yang tidak secara langsung menyebut nama dari benda/hal yang dimaksud, namun meminjam nama dari benda lain yang berkaitan dengannya untuk menggantikannya.

Contoh:

后来曾外祖母说: “老头子”, 你甭气啦。

Artinya: Beberapa setelahnya , dia berkata, ’Lupakan amarahmu, Tua Bangka.

Pada penggalan kalimat di atas terdapat gaya bahasa 借代(jièdài), pada kata yang bercetak miring terlihat bahwa kata “老头子” yang memiliki arti tua bangka merupakan kata yang dipinjam untuk menyatakan lelaki yang sudah tua, pengarang menggunakan gaya bahasa 借代(jièdài) dalam karyanya.

\subsubsection{Gaya Bahasa 反语(fănyǔ)}

Gaya bahasa 反语(fănyǔ) adalah gaya bahasa yang dalam menyampaikan makna sindiran. Contoh:

小祖宗哟，你不吃不喝，是成了仙还是化了佛? 你把娘难受死了哟!

Artinya: Apa kau pikir kau ini akan hidup abadi atau Buddha yang tidak perlu makan dan minum? Kau akan menyebabkan ibumu mati menderita!

Pada penggalan kalimat di atas terdapat gaya bahasa 反语(făny̌̌), di dalam penggalan kalimat tersebut terdapat kalimat yang menyindir dan memiliki arti yang bertolak belakang , kalimat yang menyindir terdapat pada kalimat" apa kau pikir kau ini akan hidup abadi atau 
Buddha yang tidak perlu makan dan minum?, pada kalimat ini pula terdapat arti yang bertolak belakang, karena manusia tidak dapat hidup tanpa makan dan minum. Maka pengarang menggunakan gaya bahasa ini agar cerita menjadi lebih hidup.

\subsubsection{Gaya Bahasa 层递(céng di)}

Gaya bahasa 层递(céng dì)adalah gaya bahasa yang mengurutkan atau menderetkan kalimat untuk menyampaikan maksud suatu hal.

Contoh:

我父亲行三跪六揖九吅之大礼。

Artinya: ayahku melakukakan tiga kali sujud, enam bungkukan dan sembilan kowtow.

Pada penggalan kalimat yang bercetak miring terlihat bahwa kalimat tersebut mengurutkan dari hal atau nomor yang paling kecil sampai yang besar, dari tiga sampai ke sembilan dan merupakan kelipatan sangat terlihat gaya bahasa 层递( céng dì).

\subsubsection{Gaya Bahasa 映祄(yìngchèn)}

Gaya bahasa 映祄 (yìngchèn) adalah gaya bahasa yang menunjukkan hal yang saling berhubungan ataupun berkebalikan.

Contoh:

他打了一个战，肚子咕噜噜响一阵。

Artinya: Membuat ayah menggigil kedinginan, tubuhnya gemetar, perutnya keroncongan.

Pada penggalan kalimat diatas terdapat gaya bahasa 映衬(yìngchèn), terlihat didalam penggalan kalimat tersebut hal yang sangat berkaitan, ayah menggigil kedinginan, tubuhnya gemetar, perutnya kerocongan, dari kata tubuh dan perut sudah menunjukkan anggota tubuh yang berkaitan, dan terlihat kata menggigil, gemetar dan keroncongan, terlihat bahwa si ayah sedang mengalami sakit.

\subsubsection{Gaya Bahasa 反复(fănfù)}

Gaya bahasa 反复(fănfü) adalah gaya bahasa repetisi, berdasarkan Huang dan Liao gaya bahasa ini merupakan gaya bahasa yang memanfaatkan pengulangan suatu kata atau kalimat sesuai kebutuhan pernyataan.

Contoh: 


\begin{tabular}{|c|c|}
\hline Vol.1, No.2, Oktober 2017, PP.37-48 & E-ISSN 2579-4906 \\
\hline
\end{tabular}

Artinya: ya... tidak... ya... tidak... Yang mulia... jangan pukul aku... jangan pukul aku... yang mulia.

Pada penggalan kalimat di atas terlihat adanya pengulangan suku kata, pada kalimat tersebut menggunakan gaya bahasa 反复(fănfü) yang digunakan pengarang untuk menekankan suatu permasalahan, dalam kata ya atau tidak terlihat adanya pengulangan.

\subsubsection{Gaya Bahasa 对偶(duì'ǒu)}

\section{Contoh:}

黄金火烧着爷爷的身体，蓝火苗烧着爷爷的心。

Artinya: Api keemasan membakar tubuhnya, api biru membakar hatinya.

Pada penggalan kalimat tersebut terlihat kalimat yang memiliki maksud dan hubungan, kata api keemasan dan api biru merupakan kata yang berhubungan, dan dikaitkan dengan tubuh dan hati yang merupakan satu kesatuan dari manusia, sehingga pengarang menggunakan gaya bahasa 对偶(dui'ǒu) karena memiliki maksud yang berhubungan.

\subsection{Fungsi Gaya Bahasa dalam Novel 红高粱(hóng gāoliang)}

Gaya bahasa dapat difungsikan untuk: 1) memaparkan gagasan secara lebih hidup dan menarik, 2) menggambarkan suasana secara lebih hidup dan menarik, 3) untuk menekankan ataupun menyanggahkan suatu gagasan, 4) untuk menyampaikan gagasan secara tidak langsung (Aminuddin, 2001).

Sedangkan menurut Al-Ma'aruf dalam bukunya yang berjudul Stilistika: Teori, Metode, dan Aplikasi Pengkajian Estetika Bahasa, fungsi gaya bahasa dalam karya sastra adalah sebagai alat untuk:

a) Meninggikan selera, artinya dapat meningkatkan minat pembaca/pendengar untuk mengikuti apa yang disampaikan pengarang/pembicara.

b) Mempengaruhi atau meyakinkan pembaca/pendengar, artinya dapat membuat pembaca semakin yakin dan mantap terhadap apa yang disampaikan pengarang/pembicara.

c) Menciptakan keadaan perasaan hati tertentu, artinya dapat membawa pembaca hanyut dalam suasana hati tertentu, seperti kesan baik atau buruk, perasaan senang atau tidak senang, benci, dan sebagainya setelah menangkap apa yang dikemukakan pengarang. 
d) Memperkuat efek terhadap gagasan, yakni dapat membuat pembaca terkesan oleh gagasan yang disampaikan pengarang dalam karyanya.

\subsubsection{Gaya Bahasa 比喻(b̌̀yù)}

Fungsi dari gaya bahasa 比喻 (b̌̀yù) adalah untuk memberikan efek-efek estetik atau keindahan. Didalam gaya bahasa ini juga tercipta kesan yang mendalam di hati pembaca, gaya bahasa ini sangat meninggalkan kesan yang mendalam, gaya bahasa ini juga mempunyai fungsi membuat cerita lebih konkret dan menjadi lebih menarik. Seperti contoh pada halaman 3 dalam novel 红高粱(hóng gāoliang) penulis menggunakan kalimat Nenek memudar seperti pantai di kejauhan saat lautan kabut yang mendekat semakin bergejolak. Dengan menggunakan gaya bahasa 比喻 (b̌̀yù) seperti contoh diatas, maka pembaca akan merasa lebih tertarik karena tulisannya menjadi lebih indah.

\subsubsection{Gaya Bahasa 比拟(bǐnǐ)}

Fungsi dari gaya bahasa 比拟(b̌̌ň̌) adalah untuk menghidupkan sebuah cerita dalam karya sastra agar cerita yang terkandung di dalam karya tersebut menjadi lebih menarik untuk di baca, gaya bahasa 比拟(b̌̌ň̌)juga berfungsi untuk mengungkapkan pikiran pengarang sastra dengan gaya bahasa ini pengarang sastra menceritakan ceritanya seperti benda mati yang tidak bernyawa seolah-olah benda yang hidup, dan benda yang hidup seolah-olah tidak bernyawa, seperti contoh berikut: "jalan raya membentang ke selatan, pita jalanan berliku-liku menyempit yang akhirnya ditelan ladang sorgum”. Dengan memanfaatkan gaya bahasa inilah maka cerita dalam novel ini terlihat lebih hidup dan lebih menarik.

\subsubsection{Gaya bahasa 夸张(kuāzhāng)}

Fungsi dari gaya bahasa 夸张(kuāzhāng) adalah gaya bahasa ini memiliki fungsi membuat cerita menjadi lebih menonjol, cerita yang menggunakan gaya bahasa ini juga terkesan lebih hebat, sehingga para pembaca karya sastra merasakan sesuatu yang luar biasa dalam novel ini. Seperti contoh berikut: “父亲高大雄伟漂亮” (Ayah tampak menakjubkan, ayah terlihat indah), pengarang menggunakan gaya bahasa ini dengan menggunakan kata yang sederhana menjadi kata yang luar biasa.

\subsubsection{Gaya Bahasa 借代(jièdài)}


Fungsi gaya bahasa 借代(jièdài) adalah agar kata yang digunakan menjadi beragam, selain

itu peranan gaya bahasa ini untuk melukiskan sesuatu nama yang dipergunakan sehingga kata tersebut berasosiasi dengan benda lain secara keseluruhan. Gaya bahasa ini juga memiliki fungsi sebagai perubahan, adapun kata yang diubah dalam memanfaatkan gaya bahasa ini adalah nama benda. Seperti contoh yang ditemukan dalam novel ini, pengarang menggunakan kata”老头子” (Tua Bangka) untuk menyebut seseorang yang sudah tua, melalui penggunaan gaya bahasa ini menjadikan cerita tersebut kaya akan kata. Selain itu gaya bahasa ini juga memiliki fungsi mendeskripsikan kata tersebut dengan jelas sehingga para pembaca sastra dapat mengerti dan memahami benda tersebut.

\subsubsection{Gaya Bahasa 反语 (Fănyu)}

Fungsi gaya bahasa 反语 (Fănyu) adalah memberikan kata-kata berupa sindiran yang membuat para pembaca berpikir terhadap sindirannya, dan gaya bahasa ini juga menggunakan kata-kata yang bertolak belakang dari kata-kata yang dimaksud oleh pengarang hal ini untuk mempertegas arti yang ingin disampaikan si pengarang terhadap para pembacanya sehingga para pembaca dapat merasakan kesan sindiran terlihat pada kalimat: “你不吃不喝, 是成了仙还是化 了佛?" (Apa kau pikir kau ini akan hidup abadi atau Buddha yang tidak perlu makan dan minum?). Pengarang ingin mengungkapkan pikirannya yang menggunakan kata-kata yang bertolak belakang dengan sindiran yang di ungkapkan pengarang. Selain kesan sindiran gaya bahasa ini juga dapat menyampaikan kesan humoris terhadap pembaca melalui kata sindirannya, sehingga gaya bahasa ini selain bersifat menyindir juga bersifat memberi hiburan untuk para pembacanya.

\subsubsection{Gaya Bahasa 层递 (céng di)}

Gaya bahasa 层递 (céng dì) memiliki fungsi untuk mengurutkan dari hal yang kecil menjadi besar, atau sebaliknya dari besar menjadi kecil, seperti contoh yang ditemukan dalam novel ini yaitu: “我父亲行三踭六揖九吒之大礼” (Ayahku melakukan tiga kali sujud, enam bungkukan dan sembilan kowtow). Melalui penggunaan gaya bahasa ini pengarang dapat mengimajinasikan karyanya dengan hal yang dari sederhana menjadi luar biasa dan terjadi peningkatan,

\subsubsection{Gaya Bahasa 映祄(yìngchèn)}


Gaya bahasa 映祄(yìngchèn) mempunyai fungsi menderetkan beberapa kata yang saling berkaitan, untuk membuat efek di dalam cerita menjadi berkaitan, seperti contoh yang ditemukan dalam novel ini yaitu: "Membuat ayah menggigil kedinginan, tubuhnya gemetar, perutnya keroncongan". Penggunaan gaya bahasa ini akan terlihat lebih indah dan lebih jelas karena kata tersebut saling berkaitan antara satu kata dan deretan kata lainnya dan mempunyai latar belakang yang sama untuk menyampaikan maksud dan tujuan yang ingin diungkapkan pengarang.

\subsubsection{Gaya Bahasa 反复(fănfù)}

Gaya bahasa 反复(fănfù) memiliki fungsi sebagai penegasan akan suatu peristiwa pada cerita agar cerita yang ingin di sampaikan menjadi lebih bernilai dan gaya bahasa ini juga memiliki fungsi menekankan inti pada suatu permasalahan sehingga pengarang menggunakan gaya bahasa ini agar dapat terlihat jelas inti sebuah permasalahannya. Seperti contoh berikut: “ya...tidak...ya...tidak...Yang Mulia...jangan pukul aku...jangan pukul aku Yang Mulia”. Pada penggalan kalimat di atas terlihat adanya pengulangan suku kata. Kalimat tersebut menggunakan gaya bahasa 反复(fănfü) yang digunakan pengarang untuk menekankan suatu permasalahan, dalam kata ya atau tidak terlihat adanya pengulangan.

\subsubsection{Gaya bahasa 对偶(duì'ǒu)}

Gaya bahasa 对偶(dui'ǒu) ini mempunyai fungsi untuk mengurutkan kata dan kalimat yang sama bentuknya dan memiliki jumlah yang sama, gaya bahasa ini juga menderetkan beberapa kata atau kalimat yang sama ataupun berlawanan. seperti contoh berikut ini: “黄金火烧着爷爷的身 体，蓝火苗烧着爷爷的心” (Api keemasan membakar tubuhnya, api biru membakar hatinya). Kata api keemasan dan api biru merupakan kata yang berhubungan, dan dikaitkan dengan tubuh dan hati yang merupakan satu kesatuan dari manusia, sehingga pengarang menggunakan gaya bahasa 对偶(dui'ǒu) karena memiliki maksud yang berhubungan. Selain itu fungsi gaya bahasa ini berusaha mencapai kesejajaran dalam pemakaian atau frasa-frasa yang menduduki fungsi yang sama dan gramatikal yang sama.

\section{Simpulan}

Gaya bahasa yang terdapat dalam novel 红高粱(hóng gāoliang) karya Mo Yan berjumlah 9 gaya bahasa yang terdiri dari: gaya bahasa 比喻(b̌̌yù), gaya bahasa 借代(jièdài), gaya bahasa 比 
拟(bǐň), gaya bahasa 夸张(kuāzhāng), gaya bahasa 反语(fănyǔ), gaya bahasa 层递(céng dì), gaya bahasa 反复(fănfü), 映祄(yìngchèn) dan gaya bahasa 对偶(dui'ǒu).

Adapun fungsi gaya bahasa untuk mengungkapkan pikiran pengarang dari kesekian gaya bahasa tersebut yaitu:

1. Fungsi gaya bahasa 比喻 (b̌̀yù) adalah memberikan efek keindahan didalam cerita, membuat isi yang ingin disampaikan menjadi lebih menarik dan konkret, menjadikan nilai kesan yang sangat mendalam dalam hati pembaca, menggunakan kesamaaan setiap objek agar pembaca dapat lebih mudah mengerti.

2. Fungsi gaya bahasa 借代(jièdài) adalah agar bahasa dan kata yang digunakan menjadi lebih beragam,kaya akan perubahan, menonjolkan ciri-ciri benda yang di deskripsikan secara jelas.

3. Fungsi gaya bahasa 比拟( bǐnǐ) adalah agar bahasa di dalam novel tersebut menjadi lebih hidup, menarik, dan tidak monoton.

4. Fungsi gaya bahasa 夸张(kuāzhāng) adalah digunakan pengarang untuk menggantikan kata sederhana menjadi luar biasa kedengarannya.

5. Fungsi gaya bahasa 反语(făny̌̌) adalah mengandung sindiran yang membuat kalimat terkesan humoris.

6. Fungsi gaya bahasa 层递(céng dì) adalah untuk menambahkan kesan yang hebat dan pembaca dapat mengimajinasikan urutan tersebut.

7. Fungsi gaya bahasa 反复 (fănfü) adalah untuk menekankan inti suatu permasalahan, mengungkapkan perasaan tertentu, dan menekankan harapan.

8. Fungsi gaya bahasa 映祄(yìngchèn) adalah untuk menghidupkan suasana dalam cerita.

9. Fungsi gaya bahasa 对偶 (dui'ǒu) adalah memberikan maksud yang jelas.

\section{DAFTAR PUSTAKA}

Al-Ma'ruf, Ali Imron. 2009. Stilistika: Teori, Metode, dan Aplikasi Pengkajian Estetika Bahasa. Surakarta: Cakra Books Solo

Aminuddin. 2001. Kerangka Pemahaman Sastra Modern. Malang: PPS UM. 
Cheng Chen Chien. 2007. Pesan Cerita Narasi Antara Kemanusiaan dan Alam: Asia University: Taiwan

Kridalaksana,Harimurti. 2001. Pengantar Bahasa dan Kebudayaan Jawa.Jakarta:GramediaPustaka Utama.

Kanzunnudin. 2010. Bahasa Indonesia Untuk Perguruan Tinggi. Rembang:Yayasan Adhigama.

Keraf, Gorys. 2006. Diksi dan Gaya Bahasa. Jakarta: Gramedia Pustaka Utama.

Luxemburg. 1989. Pengantar Ilmu Sastra(diterjemahkan oleh Dick Hartoko). Jakarta:Gramedia Pustaka Utama.

Moh.Nazir. 2005.Metode Penelitian. Bogor: Ghalia Indonesia

Nurgiyantoro, Burhan. 1995. Teori Pengkajian Fiksi. Yogyakarta:Gajah Mada University Press.

Nurgiyantoro, Burhan. 2005. Teori Pengkajian Fiksi. Yogyakarta:Gajah Mada University Press.

Nurgiyantoro, Burhan.2007 Teori Pengkajian Fiksi. Yogyakarta:Gajah Mada University Press.

Pradopo, Rahmat. 2011. Prinsip-Prinsip Kritik Sastra. Yogyakarta: Gajah Mada University Press.

Pradopo , Rahmat. 2012. Penelitian Stilistika Genetik: Studi Kasus Gaya BahasaW.S Rendra dalam Ballada Orang-orang Tercinta dan Blues untuk Bonnie: Universitas Gajah Mada.

Robingatun , Siti. 2013. Analisis Gaya Bahasa pada Antologi Geguritan Abang Branang Karya Rachmat Djoko Pradopo. Purworejo:Universitas Muhammadiyah Purworejo

Siswanto, Wahyudi. 2008. Pengantar Teori Sastra. Jakarta:Grasindo.

Sudjiman, Panuti. 1986. Kamus Istilah Sastra. Jakarta:Gramedia Pustaka Utama.

Sudjiman, Panuti. 1993. Bunga Rampai Stilistika. Jakarta:Gramedia Pustaka Utama.

Sumardjo. 1986. Apresiasi Kesustraan. Jakarta:Gramedia Pustaka Utama.

Sugono, Dendy. 2003. Buku Praktis Bahasa Indonesia. Jakarta:Departemen Pendidikan Nasional.

Tarigan, Henry. 1985. Prinsip-Prinsip Dasar Sastra. Bandung:Angkasa.

Pradopo, Rahmat. 2011. Prinsip-Prinsip Kritik Sastra. Yogyakarta:Gajah Mada University Press.

Yen, Yu Chuang. 2011. Analisis Suku dalam Novel Karya Mo Yan: National Sun Yat Sen University.

黄伯荣、廖序东. 现代汉语 [M]. 北京：高等教育出版社, 1991

唐瑕苓、陈澜. 科技英语中修辞格的应用浅析[J] 中国. 2013

\section{Data Penulis}

$\begin{array}{ll}\text { Nama } & \text { : Niza Ayuningtias, S.S., MTCSOL } \\ \text { Program studi } & : \text { Sastra Cina } \\ \text { Jurusan } & : \text { Sastra Cina } \\ \text { Perguruan Tinggi } & : \text { Fakultas Ilmu Budaya, Universitas Sumatera Utara } \\ \text { Hp } & : \text { +6281375401216 } \\ \text { Email } & : \text { niza.ayuningtias@yahoo.com }\end{array}$

